\title{
The Influence of Business Sector Challenge (BUSAC) Funded Grantees on Sustainability of Policy Advocacy in Ghana
}

\author{
Samuel Asihene Nyampong $\quad$ Dr. Marcella Myers $\quad$ Prof. Justice Nyigmah Bawole \\ Andrews University
}

\begin{abstract}
Theoretical development has been outpaced by the practice of policy advocacy by organizations and interest groups. Nonetheless, the relevance of grounding for advocacy campaigns has increased with the need for an understanding of contributions of advocates' to policy development and accountability. This study therefore evaluates the influence and contributions of organizations and interest groups on the sustainability of policy advocacy with focus on BUSAC Fund. The study employed both qualitative and quantitative methods to satisfy its objectives, where data was obtained through interviews and questionnaire administration. The data was obtained from 50 grantee organizations under BUSAC Fund and 5 officials of the BUSAC Fund sampled by convenience. Findings of the study revealed that the BUSAC Fund as an interest group has greatly influenced and contributed immensely to policy advocacy sustainability in Ghana's private business sector. Their contributions to policy formulation and implementation has impacted major sectors including the agriculture, industrial and the services sector. It is obvious that in ensuring policy change and sustainability of advocacy, it is important that support and lobbying is effectively undertaken through formidable interest groups and organizations. BUSAC Fund however in the delivery of their mandate has been entangled by challenges such as poor collaboration between stakeholders, low government commitment and inadequate legislative regulatory instruments.
\end{abstract}

Keywords: Business Sector Challenge, Sustainability Of Policy Advocacy, Ghana

DOI: $10.7176 / \mathrm{EJBM} / 12-19-06$

Publication date:July $31^{\text {st }} 2020$

\section{CHAPTER ONE}

INTRODUCTION

\section{Background and Rational of the Study}

The welfare of citizens of a state, region, municipalities or province cannot be well promoted if inter alia policies are not formulated and implemented as a guide for development (Meiring, 2009). Policies are therefore essential to the growth and development of a nation, and are implemented to cover various sectors of economic development. Accelerated and sustained productivity and growth is essential in countries to improve incomes and move rapidly toward convergence with the advanced market economies (World Bank, 2010). The report continued that the growing and vibrant private sector in many of countries will drive productivity enhancements, but emphasize that public policies should promote these enhancements. A policy has a central role to play in the agenda to promote sustainable development and manage climate change through provision of better infrastructure. More importantly, a policy provides signals and sets the regulatory and institutional frameworks that influence the actions of all actors, including private investors and consumers (Qureshi, 2016).

Both in practice and literature, social policy in Ghana has largely been influenced by past and recent experiences of developed Western countries. Several social welfare and economic policy prescriptions discussed in literature are derived from the experiences of these countries. Colonialism had a significant impact on developing countries including Ghana, despite the hegemonic relationship created between colonialists and the colonized. It facilitated the transmission of ideas, including those connected to social policy. Thus, the ten (10) year development plan by governor Guggisberg cannot be easily written off in the policy history of Ghana. The present state of social policy in Ghana is mostly viewed against the above context (SOPDAP, 2015).

One of the key areas for which important policies are often implemented to induce growth and development in the private sector, often characterized by businesses of different kind. The private sector is the nerve centre of socio-economic development in the world. The International Finance Corporation (IFC) (2011) recognized the private sector as a critical stakeholder and partner in economic development, a provider of income, jobs, goods, and services to enhance people's lives and help them escape poverty. The IFC emphasized that the sector cannot play its role to maximum effect if it is not provided the platform on which it can operate efficiently and effectively.

The context of establishing a conducive business environment, providing positive conditions for the performance and sustainability of formal and informal private sector companies, The implementation of various policies as a guide for business operations is necessary (Donor Committee for Enterprise Development (DCED), 2008). A strong private sector is widely recognized as key to national development and growth thereby contributing to job creation. The private sector in Ghana however, operates in an environment where a wide range of factors impact on its "cost of doing business". Some of these factors include employment and environmental legislations, consumer protection, health and safety rules, taxation, duties and tariffs. It is widely acknowledged that reducing 
the burden on businesses would not only allow them to grow but would also enhance their competitiveness of exports, reduce the exposure of businesses to economic shocks in the country thereby creating jobs, which has been one of the major objectives of the current government. In Ghana, or elsewhere the development and maintenance of the business environment is facilitated by the private sector organization (PSOs) which represents business interests. Such roles played by the PSOs enable their members to function with ease. Business Sector Advocacy Challenge Fund (BUSAC) (2016) posited that, the functional relationship between the state and the private sector is very essential to ensure the integrity of the overall business environment and serve as a check on corruption and other unacceptable business practices. The relationship between the PSOs and the government however partly takes shape upon evidence-based advocacy from private sector organizations. These advocacy responsibilities are played by few international organizations to help promote an enabling environment for the development of the private sector. These advocacy concerns are made to seek the attention of government in delivering on their policies and ensuring sustainability.

One of such advocacy organizations operating in the Ghanaian business sector is the Business Sector Advocacy Challenge (BUSAC) Fund. The Business Sector Advocacy Challenge (BUSAC) Fund was established by Danish International Development Agency (DANIDA) as a lead donor, supported by Department for International Development (DFID), United States Agency for International Development (USAID) and European Union (EU). It was designed to enhance the advocacy capacity of the private sector through public and private sector dialogue, which aimed at improving the business environment. It is reported that the BUSAC Fund has at its disposal 20 million USD within its grant making facility until 2014. This means advocacy was used as an effective tool for policy formulation and reforms (Oxford Policy Management Report, 2014). It would be much of an interest to know how business policy advocacy role being played by BUSAC influences policy sustainability. The study therefore examined the development of a sustainable policy advocacy that would suggest effective and efficient means of improving business policy advocacy dialogues with the government and other stakeholders in the private sector

\section{Problem Statement}

Foundations and nonprofit organizations often face a growing need to measure outcomes of their efforts to improve society (Guthrie, Louie, David, \& Crystal Foster, 2005). For the majority of such organizations who engage in policy and advocacy work often struggle in over ways to assess whether their hard work made a significant difference. Guthrie et al. (2005) stressed that it can take several years of building constituencies, educating legislators and other forging alliances to actually change public policy. Thus foundations that typically fund in increment of one or more years have difficulty in assessing the progress of grantees pursuing policy work. Policy advocacy organizations and public generally would also be interested knowing what differences their money made.

As mentioned in earlier submissions, the private sector in Ghana received recognition as a key socioeconomic development that would significantly contribute to the poverty reduction. The current NPP government therefore aimed at making efforts to revamp the sector which would increase productivity and hence create employment avenues in the country. Though government continues to ensure that the political and economic environment is conducive for businesses to thrive by policy formulation and implementations, the private sector in Ghana is contending with wide range of factors that affects the cost of doing business. To help drive the policies implemented by the government towards the development of the sector, BUSAC as an organization plays the role of policy advocacy. The fact that the private sector still faces developmental challenges might point out that there are problems hindering BUSAC and other related organizations in their attempt to salvage the sector. It is important therefore to ascertain the extent to which BUSAC has been successful in their mandate. Studies have been conducted on the issues of policy advocacy and its roles in policy implementation by scholars (Grossmann, 2012; Baumgartner, Berry, Hojnacki, Kimball, \& Leech, 2009; Chapman \& Wameyo, 2001). These studies also elaborate on policy advocacy and how such advocacy actions affects policy formulation and impementations. However these studies were limited to other jurisdictions or countries, not in Ghana and thus their results and recommendations may not necessarily be applicable in Ghana. The studies also demonstrated no connection between policy advocaacy and policy sustainability leavinf a pag to be filled in research. In Ghana specifically, very few studies were conducted in the ares of policy advocacy by Donor Committee for Enterprise Development (DCED) (2008), Osei-Amposah (2006) and Busac (2008). These studies dealt with aadvocaacy issues in other sectors like health and education, other than the private business sector. Whiles the study of Osei-Amposah (2006) throw light on policy advocacy organizations and their connections with policy makers, the later two focused on the significance of policy advocacy. Non of such studies relates business advocacy to sustainaability of policies, thus creating a gap in literature.

\section{Purpose of the Study}

The purpose of this research is to unearth the impact of BUSAC funded guarantees on policy advocacy sustainability in Ghana. This study would explore and assess the contributions of BUSAC in advocating for 
policies in the business sector. This would reveal the policies and projects implemented in the agricultural sector, the services sector and the industrial sector. Furthermore, this study aimed at examining how the advocacy actions of BUSAC have been beneficial towards the formulation and implementation of policies. Generally, this study would ascertain the delivery and success story of BUSAC in their quest to make an impact by enabling the private sector, including business membership organizations, trade unions and media, to influence public policy formulation.

\section{Research Objectives}

1. To ascertain the contributions of BUSAC towards the sustainability of policy advocacy in Ghana.

2. To assess the influence of BUSAC policy advocacy on the formulation and implementation of policies.

3. To identify the challenges hindering the efforts of BUSAC in the delivery of their mandate.

\section{Research Questions}

1. What are the success stories or contributions of BUSAC to the sustainability of policy advocacy in Ghana?

2. Does the policy advocacy by BUSAC influence the policy formulation and implementation?

3. What challenges do BUSAC encounter in the delivery of their mandate?

\section{Significance of the Study}

Research results generally serve as a guide to policy formulation, implementation and decision making. As such, this study would serve as an additional guide in decision making by policy makers with specific reference to the policy decisions in the business environment. This study would provide a policy direction to government as to the contributions made by BUSAC in policy advocacy, which would provide an overview of the need to engage more of such interest groups in policy dialogue to ensure sustainability. The study would further provide additional information regarding the impact of BUSAC operations on the policy formulation and implementation. This would actually allow government to decide as to whether or not provide more room for such policy advocacy organizations in promoting growth and development. This study highlighted the possible challenges faced by BUSAC playing their advocacy responsibility and the need to find solutions to such encounters in the future. Generally the study serves as reference for future research and thus contributes to academic literature.

\section{Limitations of the Study}

A key limitation of this study would be the expected difficulty in accessing relevant information from stakeholders in this field as well as key informants/respondents. It is also important note that the findings of the study may also be relatively affected by the minor inaccuracies in the data collection instruments. Even though the study have made such significant findings and conclusions, it may be accurate for making generalizations since it is does not involve any hypothetical test. The generalization of the study results is also limited because data collected on the study for analysis was impacted by personal viewpoint and values. Findings of the study should also be restricted to advocacy in the private sector business, even though some relevant issues of discussions could apply to policy advocacy in other sectors.

\section{Organization of the Study}

Chapter one of the study is the introduction, starting from the background of the study. This is followed by the problem statement, the objectives of the study, research questions, the significance of the study, the limitations of the study, the study organization and the definition of some key terms being employed in the study.

Chapter two deals with the review of related literature which seeks to examine the attempts made by different authors and researchers about the problem in question. The methodology forms the third chapter of the study which includes study design, data collection, sample size, sampling techniques, population, instruments used in collecting the data and the analytical tool intended for the analysis. Chapter four presents the results as obtained by the instruments used during the data collection and also the analysis of the data obtained from the respondents based on the research questions. Chapter five follows with the conclusion of the research with recommendations on areas which may have to be considered seriously based on the analysis and the study objectives.

\section{Definition of Terms}

Policy: an action that employs government authority to commit resources in support of a preference value. Advocacy: any action that speaks in favor of, recommends, argues for a cause, supports or defends, or pleads on behalf of others.

Policy Advocacy: refers to organized initiatives that seek to change official policy or legislation, or the manner in which these regulations are applied.

Private Sector: encompasses all for-profit businesses that are not owned or operated by the government.

Sustainability: Meeting the needs of the present without compromising the ability of future generations to meet 
their own needs.

\section{CHAPTER TWO \\ LITERATURE REVIEW \\ Introduction}

This chapter of the study involves the review of related materials to the study. It entails presentations and discussions of views and opinions of previous authors in the subject area of study. The chapter includes theoretical review of material and the empirical study for knowledge acquisition on the study.

\section{CONCEPTUAL REVIEW}

\section{Policy Advocacy and its Importance}

In view of how the term policy advocacy has been used in the academic and professional literature, some defining characteristics emerged. According to Reid (2006), foremost, policy advocacy is initiated by citizens, acting individually or as a collective often presented by nonprofit organizations. The citizens represented may have less relative power in society or may be unable to represent their own interests, such as the poor or children and other interest groups (Jansson, 2010) in the case of this study, formal and informal sector businesses. This "bottom up" approach initiated by citizen stakeholders lies in stark contrast to "top-down" public participation activities that are initiated by government institutions, including familiar outreach tools such as public hearings, citizen surveys, citizen juries, etc. (McLaverty, 2011). A second view of policy advocacy is that, it involves a deliberate process (Sprechmann \& Pelton, 2001) of influencing decision makers or influencing a social or civic agenda (Schmid, Bar, \& Nirel, 2008) in order to build political will around action (Grantmakers In Health, 2005). Policy influence and advocacy can encompasses a wide range of activities. Policy influence and advocacy is defined broadly as an intervention intended to catalyze, stimulate or otherwise seed some form of change through different forms of persuasion (Start \& Hovland, 2004).

The aim of advocacy ultimately is a change to policy (Reisman, Gienapp, \& Stachowiak, 2007) or the policy making process, generally to make it more accessible and transparent to the public; this latter goal has been called "participatory advocacy" rather than policy advocacy (Chapman \& Wameyo, 2001). Moore (2011) mentioned that in terms of policy change, the goal of policy advocacy may be to adopt, modify, or reject certain policy options. By providing the public access to the process, the public's input can at least complement the government's prescriptions for rational approaches to decision making and perhaps identify shared interests (Denhardt \& Denhardt, 2000)

In doing so, public commitment (Bryson \& Anderson, 2000), and perhaps consensus (Xu, 2005), for policy choices are enhanced. It is concluded therefore that policies developed with public input have been found to be more effective have wider distributions of benefits (Gallagher \& Jackson, 2008), and be more valued by the public (Kastens \& Newig, 2008). According to Dr. Mohammed Lamine of UNICEF, "the advocacy sector helps to influence policy makers, political and social leaders, to create an enabling policy and legislative environment that create and sustains social transformation" (Monitoring and Evaluating Advocacy, 2015, p. 34). Furthermore, others have found that public participation can also improve the government processes itself, by making them more responsive to public concerns (Nalbandian, 1999) and more adaptive to their changing environments (Koenig, 2005).

While these benefits are impressive, they are social, and they ignore the fact that advocates often engage the policy process not for broad social gain, but to advance their own specific preferences. That is, while the above benefits of public participation accrue to society, the individual groups of advocates may engage policy for more narrow benefits. It is doubtful, therefore, that the social benefits of a lively campaign among competing interests would be enough to motivate advocates to participate. What is entirely missing from the academic literature are the benefits to advocates for their policy advocacy efforts. What are policy advocates' expected outcomes for engaging the policy process? Sheldon and Wright (2013) provided some view to this questions stating that policy advocates' seek favorable policy outcomes. After all, policy advocates often advocate for specific policies. However, this answer does not hold up against thoughtful scrutiny.

First, if this were the sole measure of success for advocacy efforts, then most could only be called failures. In a pluralistic society, few get exactly what they want in policies. Especially with controversial issues that attract deep engagement by many advocacy groups with different preferences, the policy outcome is seldom a zero-sum game with clear winners and losers. As Robert Salisbury described, "Very often there is no clear resolution, no definitive conclusion to the process by which interests are articulated and pursued" (cited in Baumgartner \& Leech, 1998, p. 18). Additionally, even in those rare cases where a policy advocacy group gets its preferred policy, attribution of that outcome to their own advocacy efforts is tenuous at best. Other groups with overlapping preferences may have contributed to the outcome, making the causal link between advocacy efforts and outcomes difficult, if not impossible, to empirically establish (Baumgartner \& Leech, 1998). Further complicating the issue is the temporal length of political processes. The arc of policy change can be on the scale of decades for some 
issues (Sabatier \& Jenkins-Smith, 1999), an order of magnitude longer than advocacy organizations' programmatic and budgetary cycles. Activities with such long feedback loops are not as attractive to supporters as those with more immediate impacts.

Studies of the policy process indicate that interest groups often play a central role in setting the government agenda, defining options, influencing decisions and directing implementation (Patashnik, 2003). Burstein and Linton (2002) disclosed that interest groups are often found to have a substantial impact on policy outcomes. Research that has generated consistent evidence of influence is rare and tends to focus on narrow policy goals rather than significant policy enactments. Activity by groups with non-ideological or uncontroversial causes, for instance, may have some effect (Witko, 2006). Business is most effective when it has little public or interest group opposition (Smith, 2000). Resources spent directly to procure earmarks can be effective (De Figueiredo \& Silverman, 2006). These pointed out that policy advocacy has been considered very relevant for policy formulation, implementation and sustainability.

\section{Advocacy Groups as Policy Entrepreneurs}

There is a well-established scholarly tradition identifying individuals critical to the development and adoption of policy which are commonly termed "policy entrepreneurs". Kingdon (1995) as cited in Laing (2015), entrepreneurs were never solely responsible for the eventual adoption of a policy, but were identified as critical to the final outcome in two-thirds of cases, and unimportant in only three. Kingdon's terminology of policy entrepreneur has gained widespread acceptance, however the centrality of individuals as driving forces in policy development and change has long been discussed in policy studies (Laing, 2015). Policy entrepreneurship is an idea that emerges within many other broader theories of the policy process. It deserves elaboration, although it does not contribute a broader explanation of the policy process.

Policy entrepreneurs are individual agents in the policy-making context who are willing to sacrifice time, resources and social/political capital in order to advance a particular policy outcome (Laing, 2015). They specialize in identifying problems and finding solutions and mobilizing resources and connections across networks in order to bring certain solutions to the identified problems (Polsby, 1984). Kingdon in his elaboration of the role of entrepreneurs saw them as key coordinators who could connect together the problems, policies and politics of any given policy window. In other words, policy entrepreneurs are the key figures who will exploit political or policy opportunities effectively to bring about policy outcomes (Laing, 2015). An analyses of the policy entrepreneur have revealed a broad list of their possible functions in policy development, these were however synthesized into four-fold: displaying social acuity, defining problems, building teams and leading by example (Mintrom \& Norman, 2009).

Some entrepreneurs seem to specialize in some types of tasks more than others, yet all have the capacity to engage in these four functions at some level. However, what sets an entrepreneur apart from other agents in the policy-making sphere is variously identified as either their willingness to spend resources and take risks (Cohen, Eimicke, \& Heikkila, 2013); or their capacity to innovate, their ability to coordinate and influence key policy networks (Fowler, 1994). Typically entrepreneurs have connections across different jurisdictions and possess a strong understanding of the motivations and agendas of other players in the policy network (Mintrom \& Norman, 2009). This gives entrepreneurs a capacity then to excel at problem definition either by using events and crises (Boin, Hart, \& McConnell, 2009), or highlighting policy failure in order to put the issue on the agenda (Baumgartner \& Jones, 1993), or drawing support from actors beyond the immediate scope of the problem (Levin \& Sanger, 1994).

However, entrepreneurs would generally be unable to achieve change unaided, indeed, their real strength lies in creating teams with sufficient knowledge, skills and momentum to drive a policy through the development process and win political battles. Policy entrepreneurs often are better able to navigate the wider authorizing environment in a policy area to make key connections and draw outside support for change, as well as bring in additional knowledge and skills (Huitema \& Meijerink, 2010). Finally, policy entrepreneurs take risks and clear the path for more risk-averse decision-makers to cooperate after seeing their example. Policy entrepreneurs often run pilot programs or take responsibility for lower risk implementations to demonstrate value or get the public onside, or at the political level are willing to assume political responsibility and fight for the outcomes of policy adoption at political risk to themselves.

The individual behavioral characteristics of policy entrepreneurs may be idiosyncratic. There is no clear model of what motivations, personality or specific skills a policy entrepreneur should have, save an ability to assume those four key functional roles, although there have been psychological and behavioral studies that attempt to determine why some policy operators emerge as entrepreneurs whilst most do not (Teodoro, 2011). Nevertheless, policy entrepreneurs in various forms have been identified as key components in many theoretical models; either as originally conceived or in subsequent analysis and expansion of models (Mintrom \& Norman, 2009).

Thus policy entrepreneurs have emerged as a crucial element in studies of policy change. In business policy, policy entrepreneurs have been identified as critical drivers of policy development in a number of jurisdictions and 
cases (Huitema \& Meijerink, 2010). Strategies for advocating the policy process thus shift from providing mutually agreeable terms of exchange between policymakers and interested parties to strategies of empowering policy champions to advance options within a policy sphere. From advocacy and influence perspective, the idea of champions and entrepreneurs is of particular interest to scientists and researchers, as the literature readily establishes that science and access to convincing information can significantly aid entrepreneurs in winning internal battles (Gupta, 2009).

Yet there also remains the potential for influence-seekers themselves to play an entrepreneurial role. Effective entrepreneurs, as established previously, generally have credibility and social capital sufficient to break down barriers and create momentum towards policy outcomes. Because advisors and scientists may come to occupy institutionalized positions within the policy process, this can create a platform for policy entrepreneurship (Mintrom \& Norman, 2009). Although entrepreneurial analysis is infrequently applied to scientists and experts, recent studies of the nuclear power industry (Duffy, 1997) and public health policy (Craig, Holly, Jada, \& Martha, 2010) in the United States have indicated the capacity for experts to assume the roles of policy entrepreneurship and to provide momentum to policy reform, albeit with limitations if they do not also hold positions of authority within relevant political or bureaucratic policy structures.

\section{Significance of Policy Interest Groups to Championing Development}

The interest group factor identified in previous literature reviews (Baumgartner \& Leech, 1998; Burstein \& Linton, 2002), research of policy change was general support. This often included idea development, public support and advocacy. Congressional lobbying, generated constituent pressure and research were also somewhat commonly cited tactics. The most frequently credited types of interest groups were advocacy organizations, including ideological and single-issue groups as well as identity groups. According to research of policy change, these groups were partially responsible for more than one-third of all significant post-war policy changes. Academics and business interests, especially industry trade associations and peak associations, were also judged important.

In 2012, Grossman wrote, "According to policy historians, interest groups are involved in significant policy enactments quite often (p. 27). Interest groups were partially credited with significant new laws passed by the American Congress. Policy interest group factors which play a role in policy making in every type of federal policy making venue, but most often in bureaucracies. Interest group activities are sometimes mentioned as the sole explanatory factor in these explanations; more commonly, they are mentioned in combination with other factors such as focusing events, media coverage, negotiations among government officials and the support of specific policymakers. Even though there are important differences in explanatory factors for policy adoption in different branches of government in the United States of America, interest groups are commonly credited actors in all three branches.

In one instance, Studlar (2002) describes a case of brinksmanship between administrative agencies and regulated corporate interests over the broadcast ban on tobacco advertising. In another context, Studlar (2002) reports, the administration partnered with interest groups in the legislature by acting to classify tobacco as a carcinogen: Second hand smoke became a major issue after the Surgeon General's report of 1986'.

Interest groups are credited with policy changes in the courts as well, even though courts are the venue where the average interest group is less involved (Schlozman \& Tierney, 1986). The research function of interest groups reportedly made a difference in policy outcomes as well. Reports by non-governmental organizations were associated with over 9 percent of significant enactments. Yet not all factors related to interest groups were judged commonly influential. Resource advantages on one side of an issue, new group mobilization, protests and a group switching sides in a policy debate were each mentioned infrequently.

When specific types of interest groups are mentioned, business interest groups are credited most often. Advocacy organizations are mentioned far more often in explanations for post-war policy change than unions, professional associations or business interests. This is consistent with (Berry, 1999) finding that citizen groups had a stronger influence on the government agenda than business interests. It also reflects the fact that business groups are disproportionately likely to lobby against policy changes rather than give them the needed support (Baumgartner, Berry, Hojnacki, Kimball, \& Leech, 2009).

The strong relative influence of advocacy organizations is striking, given that business and professional interests outnumber them by a large margin (Walker Jr, 1991), but it reflects their unique advantages in reputation and perceived public support (Berry, 1999; Baumgartner et al, 2009; Grossmann, 2012). Studies of the policy process indicate that interest groups often play a central role in setting the government agenda, defining options, influencing decisions and directing implementation (Baumgartner \& Jones, 1993; Berry, 1999). In their metaanalysis of studies of influence, Burstein and Linton (2002) show that interest groups are often found to have a substantial impact on policy outcomes. Yet most studies of influence look at particular issue areas and organizations, rather than generalize across a large range of cases (Baumgartner \& Leech, 1998).

Studies of influence that do attempt to generalize suffer from the inherent difficulty of measuring influence. One type of study uses surveys or interviews with interest group leaders or lobbyists, mostly relying on self-reports 
of success (Holyoke, 2003; Heaney, 2004). This tells us only what group tactics are associated with success as perceived by each group. A second type of study selects a measure of the extent of interest group activity. But there is some evidence that contributions may raise the level of involvement in legislation already supported by the legislator (Hall \& Wayman, 1990). A third type of study changes the dependent variable from policy influence to lobbying success. This allows policy makers to assess who is on the winning side of policy debates based on interest group coalition characteristics (Baumgartner et al, 2009; Mahoney, 2008). Yet these assessments do not incorporate the many other factors unrelated to interest groups that predict the success and failure of policy initiatives.

General studies of interest group influence have been able to definitively demonstrate only conditional and small effects, often on minor policy outcomes. Even studies of lobbying success, rather than influence, tend to demonstrate the potential to stop policy change rather than to bring it about (Baumgartner et al, 2009). Despite the many case studies that find evidence of interest group influence on major laws (Baumgartner and Jones, 1993), administrative actions and court decisions (Melnick, 1994), aggregate studies of influence based on the resources spent by each side fail to demonstrate that interest group activity can lead to major policy enactments.

Policy makers have also sought to use network analysis to understand how interest group relationships might lead to policy influence. Heinz, Laumann, Nelson and Salisbury (1993), for example, find that most policy conflicts feature a 'hollow core', with no one serving as a central player, arbitrating conflict. Grossmann and Dominguez (2009), in contrast, find a core-periphery structure to interest group coalitions, with some advocacy groups, unions and business peak associations playing central roles. Yet most network analyses are based on endorsement lists or reported working relationships, rather than influence. There has been no effort to look at a large number of significant policy enactments over a long historical period and assess the pattern of interest group influence.

Surprisingly, interest group influence does not seem to follow directly from group mobilization. Policy makers also find interest group influence where a few groups have large and consistent roles in policy making, rather than when lots of groups mobilize. Relative interest group influence may also not follow from resource advantages. Monetary advantages on one side of a policy issue, the other key factor that policy makers typically investigate as a determinant of interest group influence (Baumgartner et al, 2009), was almost never mentioned by policy historians as an important determinant of interest group influence.

Advocacy groups were also seen as more influential than business interests, professional associations or unions, even though they are less numerous and have fewer resources. If these historical accounts are to be believed, it suggests that the mechanism for interest group influence is not likely to be resource exchanges. The discrepancy between the common claims of interest group influence in case studies of policy making and the difficulty finding consistently influential tactics in the quantitative literature on influence. Policy makers typically investigate influence by measuring the amount of interest group activity directed toward a specific tactic, (Baumgartner \& Leech, 1998).

If more groups and more resources do not lead to more influence, these measures should not be expected to be consistently associated with influence. Policy makers often assume that all interest groups with the same resources and the same strategies should be equally likely to be influential. In other words, policy makers investigate which groups succeed by comparing resources and strategies. If interest group influence typically results from general support offered by advocacy organizations with particular types of reputations, rather than resource advantages or the strategies that groups employ, these methods will not help us understand how some interest groups succeed where others fail.

To the extent that analysis of policy change offers a clear perspective on the mechanisms of interest group influence, it points toward the importance of a small number of central groups with reputations for constituency representation. This includes advocacy organizations representing important public groups, trade associations representing key industries and inter-governmental actors. This is consistent with evidence that interest groups seek to develop reputations for representing stakeholders (Heaney, 2004) and that the few interest groups that develop these reputations are repeatedly involved in policy making (Grossmann, 2012).

\section{THEORETICAL EVIEW}

This section of the chapter entails the discussions on various theories that underpin policy advocacy. These theories explains and gives a good understanding of how policy changes occur and the manner in which various kinds of advocacy strategies and conditions relates to policy change. These theories again would enlightened the study on the common advocacy strategies that are likely broader advocacy efforts.

\section{Punctuated Equilibrium Theory}

According to Baumgartner, Bryan and Wilkerson (2002) the Punctuated Equilibrium Theory deals with broader signs of policy change, a process that can be observed by investigating variations between longer periods of policy stability, or "equilibriums," and relatively short periods of change, or "punctuations". The theory focused on clarifying abrupt vicissitudes in the policy environment that could not be understood by only applying institutional 
models or models of collective action (True, James, \& Glenn, 2007). The theory has been applied in many policy studies specifically to situation in which stable subsystems are disrupted by sudden policy. Baumgartner, Berry, Hojnacki, Kimball and Leech (2009) have outline three major conditions of the "standard model" of the Punctuated Equilibrium Theory.

1. They outlined that political conflict is expanded beyond the confines of expert-dominated policy subsystems, sometimes referred to as "venue switching."

2. They secondly purported that policy images, or the way in which policy problems and solutions are understood, are the primary mechanisms of change.

3. Third, policymaking exists in an overlapping system of partially independent institutional venues.

The Punctuated Equilibrium Theory generalizes this basic framework, focusing on how information is exchanged and filtered in policy subsystems. Generally the theory emphasizes on the role of the processing of information in a policy making system. Informational processing involves collecting, assembling, interpreting, and prioritizing signals from the policy environment (Baumgartner, Berry, Hojnacki, Kimball, \& Leech, 2009). Approaches to information tend to focus on proprietary conceptions, where information is private and to some degree "privileged." Differently, the general approach to Punctuated Equilibrium Theory considers the great accessibility of information in most policy subsystems. Amidst the milieu of policy information in contemporary subsystems, how do policymakers decide which issues are important? Furthermore, once the most pressing issues have been identified, how do policymakers determine the best policy solutions to address those issues? This "selective attention process" has important implications for policy subsystems. Punctuated equilibrium is the process of interaction of beliefs and values concerning particular policy (termed policy images) with the existing set of political institutions (venues of policy action). It explains both periods of extreme stability and short periods of rapid change. Policy venues are the institutional locations where authoritative decisions are made concerning a given issue, and different constituencies can be mobilized (Baumgartner \& Bryan, 1991). Actors seek new venues when they need to adapt to institutional constraints in a changing environment - they resort to framing processes or policy images. Each venue carries decisional bias because both participants and decision-making routines differ. As the venue changes, the image may change as well; as the image of policy changes, venue change becomes more likely (Baumgartner \& Bryan, 1991).

The theory go on to explain that the concepts of "bounded rationality" and "rational actor-based decisionmaking" are also very important in the processes of policy analysis and advocacy. Bounded-rationality is a fundamental concept for explaining individual and collective decision-making in organizational and social network theory (Kadushin, 2012). Simply the theory in this section posits that policy actors make decisions in an information rich environment, but because of cognitive and institutional limitations they cannot devote attention to many policy issues at once a phenomenon known as serial processing, or as mentioned, selective attention processing.

Moreover this theory outlined that in effect, major subsystems often have negative consequences for dominant stakeholders groups, resulting in counter-mobilizations to "set things right" so subsystems rarely veer too far from "equilibrium" (True, James, \& Glenn, 2007). Ideas, or "images" and institutions, or "venues," play a critical role in supporting policy monopolies: "Where the institutional venues of decision-making are stable, and where a positive policy image supports a given policy, powerful negative feedback processes can operate, creating a strongly homeostatic system that generates stable policy outcomes for decades" (Baumgartner, Bryan, \& Wilkerson, 2002). Institutional venues limit who can participate in policy discourse, while policy images support particular "idea sets" that shape how policymakers think about and discuss policy issues.

This theory help explains the context of the study that, like seismic evolutionary shifts significant changes in policy and institutions can occur when the right conditions are in place. It is however applicable to this study because the policy advocacy role played by BUSAC are large and for the fact that there exists strong capacity for media advocacy. With regards to this theory it has emerged that in order for BUSAC to build up a stronger framework in achieving their objective of policy advocacy, then they must ensure amore collective action. Institutionalizing their operation more effectively would foster policy discussions easier and efficient. The idea of policy images and venues of action is helpful, and the theory of punctuated equilibrium has been used widely in the literature. How policies and proposals are framed and how actors strategically select venues can have a great impact on the success of change. Policy-makers therefore have to think carefully about what policy image they want to create and which venues of action they select in order to bring other stakeholders (including the public) onboard.

\section{Coalition or Advocacy Coalition Theory}

The Advocacy Coalition Framework (ACF) argues that "advocacy coalitions" operate within a "policy subsystem." Subsystem participants with similar policy beliefs form advocacy coalitions comprised of people from a variety of positions (elected and agency officials, interest group leaders, researchers, etc.) who share a particular belief system (Sabatier, 1998). 
In policy networks, advocacy coalition theory articulates the mechanisms of group formation, or why certain policy participants choose to cooperate, while others do not. In network terms, this process can be interpreted as a selection activity, modeled as how likely policy actors are to interact with each other (Henry, 2011). More formally, if two individuals have matching characteristics in greater than expected proportions in comparison to the rest of the network population, then they are more likely to form ties (Kadushin, 2012). In policy networks, policy-related beliefs facilitate connections between actors in the same advocacy coalition (Henry, 2011). It appears then that policy beliefs enable network ties both within and between advocacy coalition members.

The theory conceptualized that policy-related beliefs are deep core beliefs. Deep core beliefs are normative in nature and extend across policy subsystems. Deep policy core beliefs are a product of childhood socialization and are very difficult to change (Sabatier \& Weible, 2007). These policy believes according to the theory are also policy core beliefs, which are interpretations of deep core beliefs applied to whole policy subsystems. These include the relative importance of different policy-related values, whose welfare matters, and the proper functions of private entities and government authorities in policy matters. Policy core beliefs also shape how policy actors arbitrate the relative urgency of different policy problems within subsystems, as well as the fundamental causes of (and often the appropriate solutions for) those problems.

Likewise, Henry (2011) finds policy core beliefs are stronger predictors of tie formation within collaboration networks than perceived influence. Interestingly, however, perceived influence was an important predictor of collaboration within ideologically based coalition (Henry, 2011). BUSAC in their quest to ensure a more successful achievement of their objectives need to form stronger coalition and follow these components explained in the coalition theory in their delivery.

\section{CHAPTER THREE}

\section{RESEARCH METHODOLOGY}

\section{Introduction}

This is the section of the study in which the various methodologies of research employed by the study are outlined. Kumekpor (2003) asserted that the choice of research methodologies and their use to achieve a research purpose helps to streamline and ease the collection and analysis of data. The method of research thought applicable for this study is well informed by the types of questions to be answered. The major question as to what influence the operations of BUSAC in the delivery of their mandate had on the sustainability of policy advocacy in Ghana, prompted the researcher to adopt the descriptive research method to achieve the objectives. This therefore implies that this study followed follow every systematic procedure involved in descriptive research method.

\section{Organizational Description (Business Sector Challenge (BUSAC) Fund as a Business Advocacy Organization in Ghana)}

In 2004, DANIDA as part of the broader Business Sector Programme Support launched BUSAC Fund as a private sector support mechanism. The first phase of the BUSAC Fund, which was supported by DANIDA, DFID and USAID, ended in February 2010 after six years of operations. During this phase, the BUSAC Fund provided three hundred and sixty-two (362) grants to business groups and associations spread over all the ten regions of Ghana to undertake advocacy activities aimed at improving the Ghanaian business environment to dialogue with government in policy reforms and formulation (Oxford Policy Management Report, 2014).

The fund provided an efficient process for awarding and managing grant. It further improved public-private dialogue due to the application of robust advocacy process tools, for which duty bearers have listed to provide convincing arguments. The fund created an impact by enabling the private sector, including business membership organizations, trade unions and media, to influence public policy formulation by undertaking appropriate research, developing evidence based policy positions, advocating those positions with government and other private sector institutions and organization who may be targeted by the action. The fund provides grants to: farmer based organizations, business associations, and trade unions and media houses. And all these organization associations are categorized within the private sector (Oxford Policy Management Report, 2014). Advocacy of policy reforms and formulation has helped to build capacities of private sector organizations (PSOs) to identify issues, understand issues, develop proposals with responses, influence policy makes and fellow up into business environment challenges which hinder their development and growth in the world. It was noted that Busac in their delivery collaborates with an important organization that provides a global platform for such advocacy groups.

\section{Research Philosophy}

In undertaking research of this nature, it is essential to understand and consider the different philosophies of research which describes beliefs, perceptions, assumptions and nature of truth ad reality. Gaining relevant understanding of such concepts influences the process of undertaking research from the design through to the conclusions (Flowers, 2009). Blaikie (2000) also mentioned that philosophical aspects of research is a series of choices which needs to be considered by researchers since such choices connects with dealing with the problem 
under study. According to Galliers (1991), the positivist (sometimes called scientific) and interpretivist (also known as anti-positivist) are the two major research philosophies identified in the Western tradition of science. The point of positivist is deduced from that of natural science and is characterized by the hypothetical test development from existing theory means of measuring observable social realities. This position supposes the social existence is objective and external and that knowledge is effective only if it is grounded on observations of this external reality (Galliers, 1991). The positivist view of research is objective in theory by using scientific methods of research as opposed to being subjective. Methods associated with this paradigm include experiments and surveys where quantitative data is the norm.

Interpretivist or non-positivist on the other hand, contends that intervention in reality can only be understood by the means of subjective interpretation. The investigation about phenomena in their natural state is key to the interpretivists, together with the acknowledgement that scientists cannot avoid affecting those phenomena they study. Interpretivists admit that there may be many interpretations of reality, but maintain that these interpretations are in themselves a part of the scientific knowledge being pursued (Galliers, 1991)

This study was composed on the methods and ideologies of both interpretivists and the positivist's paradigms. This is based on the fact that the study employed both quantitative and qualitative techniques of research to satisfy its objectives. On one hand, the study utilized the techniques of interpretivists approach to research such as the use of interviews, observation and text data to make deductions and conclusions. In other cases, the techniques of the positivists like the use of questionnaires to generating quantitative information for analysis upon which conclusions were made.

\section{Inductive and Deductive Reasoning to the Study}

A deductive reasoning or approach is concerned with developing hypothesis based on existing theory, and designing a research strategy to test hypothesis (Wilson, 2010). It has also been stated that deductive means reasoning from a particular to the general or deductive reasoning is geared towards making inferences and generalizations. That is, if a causal relationship or link seems to be implied by a particular theory or case example, it might be true in many cases. A deductive design might test to see if this relationship or link did obtain on more general circumstances (Gulati, 2009).

Inductive reasoning on the other hand deals with the exploration for pattern from observation and the development of clarifications for those patterns through series of hypotheses (Bernard, 2011). Inductive reasoning is subjected to an observation that results in generalizing an idea or theory about a specific topic. It therefore has a broader perspective of conclusion as compared with deductive reasoning. Whiles deductive reasoning is related quantitative study, inductive approach relates with qualitative research study. This study was based on both deductive and inductive reasoning to research since it involve a quantitative analysis of some issues of concern to the study, and also aimed at describing and interpreting events and the happening of policy advocacy from the perspectives and opinions of people.

\section{Research Design}

Descriptive research provides a picture of situations under investigation as they naturally occur/happens (Burns \& Grove, Understanding Nursing Research, 2003). Burns and Grove further explained that descriptive research may be employed in justifying current practices and making judgements, all of which enables the development of theories. With descriptive research, the researcher is aware of the nature of the problem. From the theoretical perspective, descriptive research describes phenomena as they exist and may help uncover new facts and meaning. It is used to identify and obtain information on a particular problem or issue.

The purpose of descriptive research is to observe, describe and document aspects of a situation as it naturally occurs (Polit \& Hungler, 1999). This method is considered appropriate for this study because there is an awareness of the phenomenon of policy advocacy actions by BUSAC in aid of promoting good businesses environment and policy sustainability. The adoption of descriptive research method would help provide a true picture of the operations of BUSAC as it occurs. The method is applicable to describe details of the practices of BUSAC and making judgments that will enable the development of theories. The phenomena of policy advocacy undertaken by BUSAC as it exists was uncovered with facts for suggestions towards improvements.

Knupfer and McLellan (1996) purported that descriptive research can be either quantitative or qualitative. It entails the collection of data which describe event and then organizes, tabulates and describe the data for relevant conclusions towards decision making. In order to have a clearer picture, description and analysis of the issues understudy, the researcher adopted both quantitative and qualitative approaches depending on which objective under discussion. Quantitative research primarily concerned with observable and measurable phenomena involving people, events or things, and establishing the strength of the relationship between variables, usually by statistical tests (Couchman \& Dawson, 1995). A quantitative research primarily rests upon numbers aggregated into statistics, to enable the researcher to interpret obtained data and reach conclusions (Cormack \& Benton, 1996).

Creswell (2003) also referred quantitative approach as that which is focused on the collection and analysis of 
numerical data and statistics. The objective of quantitative research is to develop and employ mathematical models, theories and/or hypotheses pertaining to phenomena. This study employed strategies of inquiry in quantitative descriptive method in some instances to achieve some of its objectives through the collection of quantifiable data on predetermined instruments that yielded statistical data for analysis.

According to Burns and Grove (2003) qualitative approach is a systematic, subjective approach used in describing life experiences and giving meaning to them. The qualitative descriptive research design was considered appropriate because it allows for thorough and detailed investigation of the research problem in real life situation without the manipulation of variables at the micro-level.

Objective 1 and 3 of the study which aimed at examining the contributions of BUSAC and challenges hindering them in the delivery of their mandate required the qualitative information from the organization. This was collected from already existing reports and other relevant documents or information's from the organization. The second (2) objective of the study however required a quantitative approach which used a data to be collected from using a well-designed questionnaire. A quantifiable data was required to address this objectives through quantitative research. It is thus clear from these submissions that the study employed both qualitative and quantitative methods of research to accomplish its objectives.

\section{Population}

Neuman (2006) defined population as the entire units or objects targeted by a researcher where units to be sampled are specified. It also shows the geographical location, and the temporal boundaries within which a research is carried. The populations of concern to this study constituted all personnel working in connection with Busac, capable of providing the needed information on the study, specifically with regards to achieving the second research objective. These included Grantee Organizations and Fund Management Unit of Busac. The management of Busac also constituted the study populations. The target guaranteed organizations of importance to the study covers all the 10 administrative regions in Ghana.

\section{Sampling Technique and sample size}

Purposive and convenient sampling techniques which are non-probability sampling techniques were employed by the researcher in the selection of the respondents to provide the needed information on the study in aid of satisfying the second objective of the research. Purposive sampling, also referred to as judgment, selective or subjective sampling is a non-probability sampling method that is characterized by a deliberate effort to gain representative samples by including groups or typical areas in a sample (Patton, 2009). The purposive sampling technique is being employed here since the study relies on judgment to selecting respondents that can provide accurate information on the study. Member of the Grantee Organizations and Fund Management Unit of Busac formed part of the respondents selected by this technique. Respondents were selected on purpose by the researcher.

Convenient sampling method on the other hand is a method of drawing representative data by selecting people because of the ease of their volunteering or selecting units as a result of their availability or easy access. The advantages of this type of sampling are the availability and the quickness with which data can be gathered. This method was used in selecting respondents to solicit vital information's on the study but on the convenience of the researcher. The study used this method of sampling to obey research ethics.

These sampling techniques were employed specifically to solicited information from respondents on specific issues on the influence that the Busac Fund advocacy has on the formulation and implementation of policies in Ghana. It was also to solicit information on the challenges encountered by Busac Fund in carrying out their mandate to satisfactions and the way forward. The application of the above discussed sampling methods resulted in selecting 55 respondents. Out of this number 50 ( 5 selected from each of the 10 region) of them were beneficiaries or Guaranteed Organizations, and the remaining 5 respondents constituted some officers of Busac Fund.

\section{Data Collection Instruments and source of data}

Per the respective objectives of this study, both primary and secondary sources of data were collected to achieve the purpose of the study. Secondary data which is readily available information was gathered from the organizations reports and other important documentations which are usually referred in research as archival data. These included the following:

- $\quad$ BUSAC Fund annual reports

- Report on increasing agriculture production through policy advocacy

- Reports on the development of Ghana's agriculture and infrastructure through business advocacy.

- Report on growing Ghana's industries through business advocacy

- $\quad$ Report on growing Ghana's SME sector through advocacy

- Review of evaluations and Impact Assessment Reports of Busac Fund.

All the above mentioned reports were completely reviewed and discussed to provide answers to the objective 
1 and 3.

Moreover, primary data was collected by use of questionnaires designed to capture various variables that will assist in satisfying objective 2. Most questions were however closed ended questions, giving options to respondents from which they pick an option. Details of the questionnaire also assisted in achieving some portions of objective 1 and 3. The interview method was also employed to solicit information's from the management of Busac on specific issues that would help deduce a concrete finding for the study. Questionnaires were self-administered to the grantee and beneficiary organizations on visit to the project sites to ascertain and confirm more success stories or facts of the policy implementations, thus observations by researcher on the ongoing activities were also used in the discussion of findings of the study.

\section{Ethical Considerations}

To ensure that the ethics of research were followed accordingly, an informed consent form was sent to Busac where the study is focused, to seek their permission on any activity to be undertaken by the researcher in their domain. This paved way to obtain some important document and reports upon which analysis was based. This also provided respondents some levels of confidence to be able provide freely the needed information's on the study without fear and panic. Due process was also followed in organizing the entire report that would not tarnish the image of the organizations but to give suggestions or recommendations towards improvements.

Questionnaire used for this study was also designed to follow the right attributes that a questionnaire should possess in order not to offend respondents. Thus questions such as double barrel questions, leading questions and ambiguous questions were avoided. In order not to exert unnecessary pressure on respondents, questionnaires were distributed ahead of time to provide enough time for completion.

\section{Data Analysis}

The analysis of data made use of both qualitative and quantitative techniques. The thematic method of qualitative analysis was used with respect to objectives 1 and 3 which involved qualitative data. The thematic method is a foundational method for qualitative analysis which involves thermalizing meanings with the view of gaining understanding from data (Braun \& Carke, 2006). In applying this technique, a thematic framework was developed on the basis of theoretical interest that guided the study or on the basis of important issues which emerged from the data. Thematic analysis of data largely in this study thus means findings were more interpretive and inductive with reference to revealing issues especially with regards to objectives 1 and 3 .

On the other hand, information collected with questionnaires were coded or quantified in to numerical values on which analysis was conducted using SPSS (Statistical Package for Social Sciences). This helped satisfy objective 2 and paved way for an additional insight into achieving the third specific objective of the study. Statistical techniques in forms of descriptive, percentages and charts were used to deduce meaningful information from the data.

\section{CHAPTER FOUR RESULTS AND DISCUSSIONS Introduction}

This chapter delves in to the analysis of results from the data gathered on the study and the discussion of findings derived from the results. The analysis presented to depict the objectives underlying the study, hence each section of the chapter is developed on the objectives one after the other.

\section{Contribution of BUSAC Fund towards policy advocacy sustainability in Ghana}

Critical analysis of archival records retrieved from the BUSAC Fund depicted that they have contributed immensely to sustain policy advocacy in Ghana. In ensuring that policy advocacy is a continuum and does not come to a stand, several strategies were implemented by Busac to sustain their advocacy mandate. Sustainability of policy advocacy was first demonstrated by Busac through their contributions to the Ghanaian economy, they have achieved success in the implementation and execution of many projects. Generally, Busac fund in the past decade have strengthened the policy advocacy capacity in the development of private sector businesses, a sector that has been one of the main "drives" of the economy. Busac has been able to continuously engaged government in collaboration with the private sector organizations to dialogue on the way forward to ensuring a conducive business environment for them to thrive. Busac therefore has become a platform or a medium through which the private sector organizations direct some of their concerns and grievances to the government.

For instance, in 2015 Busac contributed to the achievement of policy reforms, new legislations and also supported about advocacy activities (e.g. agriculture inputs and extension delivery, infrastructure provision, enforcement of regulations and standards, capacity building and skills development, access to market and access to finance) which were aimed at regulatory changes and enforcements to enhance the business environment. Such collaborations have benefited private sector organizations (PSOs) through their active participation in public policy 
formulations. The Busac fund in sustaining or championing advocacy policies have offered grants to PSOs in the sectors of agriculture, industry and the services sector. Figure 1 below shows a piece of contribution of Busac fund in 2014 and 2015:

\section{圈Agriculture $\quad$ Industry $⿴$ Services}

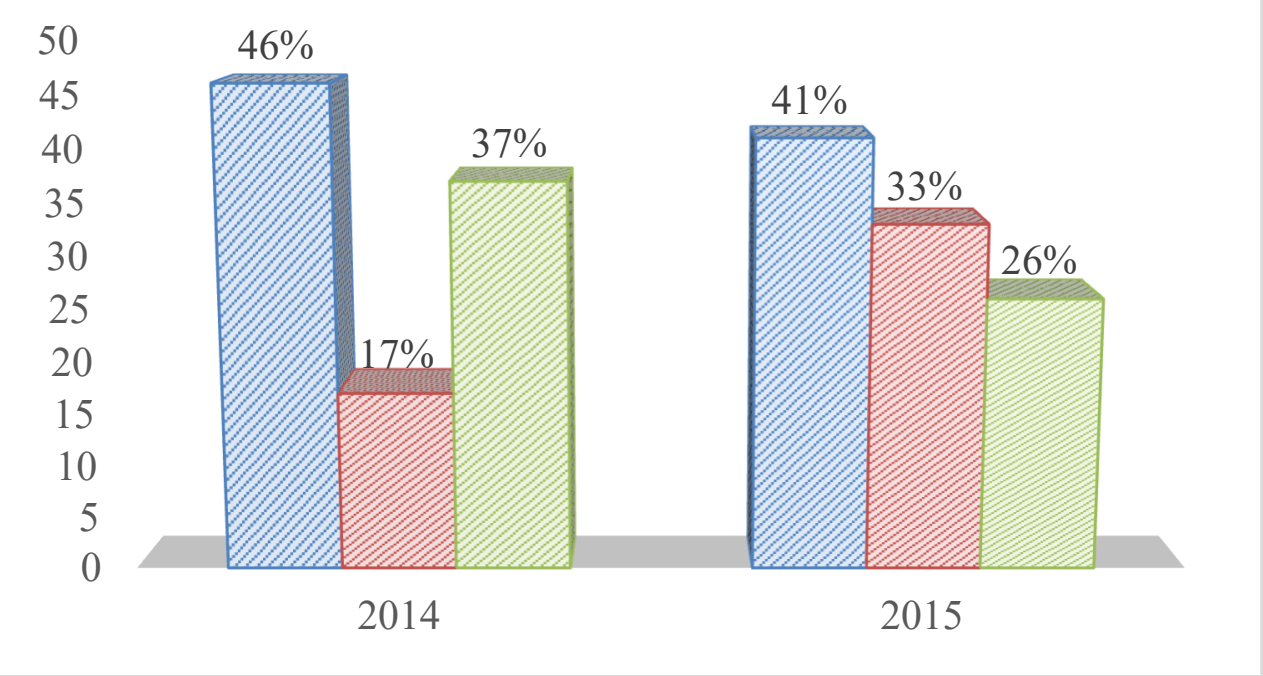

Source: BUSAC Annual Report, 2014, 2015

Figure 2: Contributions of BUSAC FUND to the Major Sectors of the Economy

It is depicted that high percentage of Busac Funds were dedicated to the agricultural sector, a sector which has experienced decline in growth in recent times as depicted on Figure 2 below. The industrial and services sector has also been given the needed attention, depicting that the three major sectors of the economy has received tremendous contributions from Busac.

The Trend of Agriculture and Economic Growth in Ghana
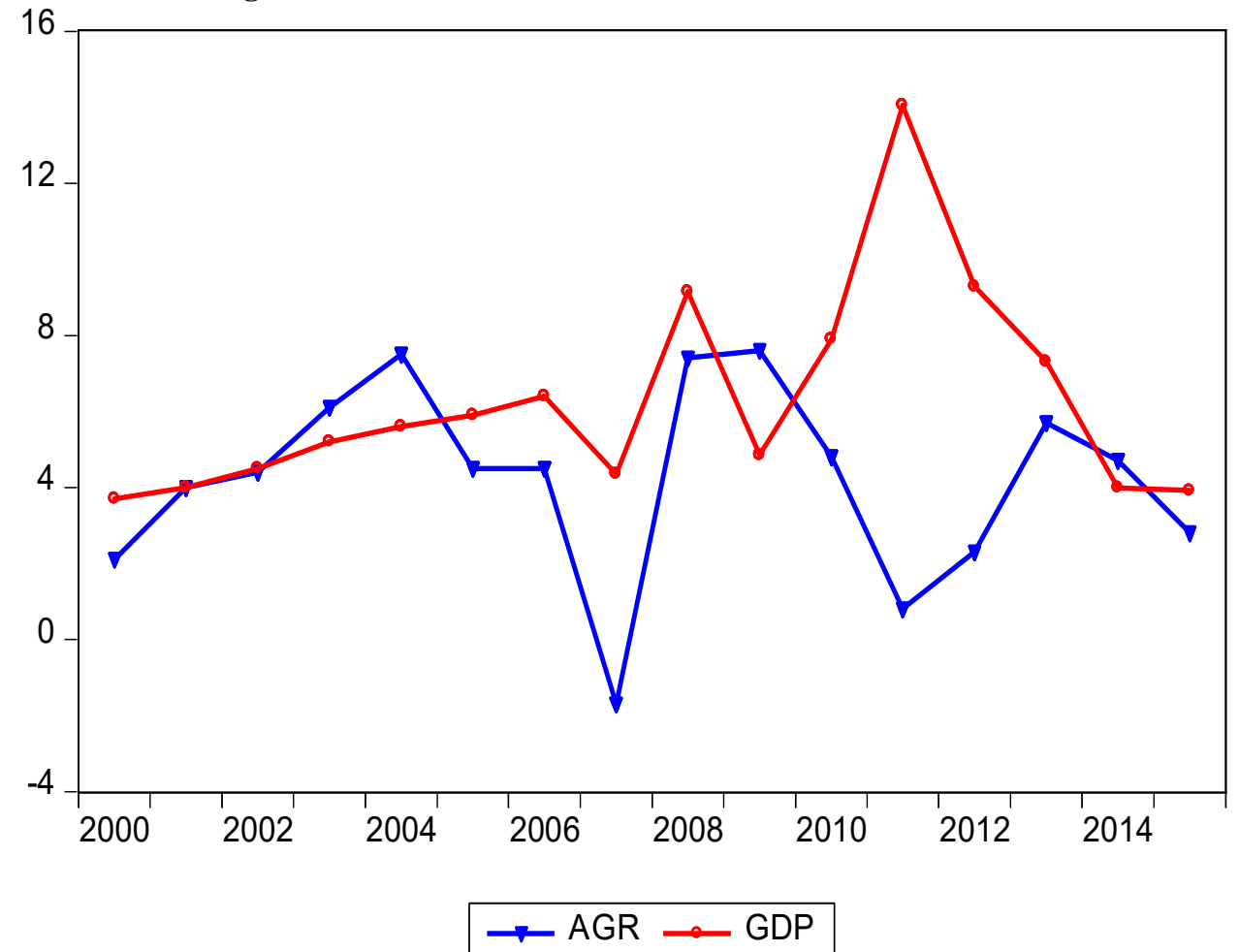

Figure 2 Trend of Agriculture Growth and Economic Growth

Strengthening the capacity and ensuring policy advocacy sustainability, it was further deduced that Busac funds regularly organized training programmes for the private sector representatives on issues of "Financial 
Management" and on "Parliamentary Practices and Procedures". These training programmes were meant to enhance business associations to advocate the removal of business barriers in the business environment. In the case of financial management training, it was of the view that it is important to build the capacity of business leaders with requisite financial management skills to enable them manage their advocacy grants effectively thus ensuring sustainability of advocacy. The parliamentary practices and procedures training on the other hand, was aimed at equipping the private sector and civil society to take up the responsibility of effective engagement of Ghana's parliament in policy implementations and decisions that impact the business environment. Such effective and success dialogues would help improve the businesses and also sustain their courses of action.

Moreover, as established in earlier submissions, Busac funds has contributed to the three main sectors of the Ghanaian economy (agriculture, industry, and services). All of such activities were supports given by Busac to various private sector organizations to strive and sustain their operations. These activities or projects has thus serve as empowerment to business or beneficiaries which gradually sustaining them in business. In the agricultural sector, Busac fund has made several contributions towards growth and development of the sector. In the sector, policy advocacy sustainability is ensured by means of empowering farmers to improve on their skills through various training programs and support such as financial and business management training, training on rules and guidelines to ensure good connection with industry players that would pave way for value for money and other forms of training. Engagement with stakeholders which include the ministries and agencies responsible for projects, the Ministry of Food and Agriculture (MOFA) through the Ghana Irrigation Development Agency has helped in the achieving most advocacy policy programmes. It was further deduced that with support from DANIDA, USAID and EU, the Busac Fund provided many Private Sector Organizations (IPOs) including business association grants in the agriculture sector that helped them to improve their growth and sustain production.

Knowing that the sector is mostly dominated by smallholder farmers who produces food and cash crops and thus the sector being the largest source of employment in the country. Busac Fund has highly focused on supporting business advocacy in the sector to improve the livelihood of farmers, food security, land use rights and genderbased constraints. A mere increase in food production would definitely not solve the plight of farmers in the sector. To ensure sustainability of farmers operations, Busac Fund facilitated private and public sector dialogue to enhance a conducive environment for creating market opportunities connecting farmers and buyers, understanding standards and pricing, contributing to increasing the income level of farmers and market efficiency throughout the value chain.

To be able to establish the facts on the ground, many of the farm businesses and associations were visited for self-assessment. Some of which included:

- $\quad$ The Bee Keepers Association (who successfully advocated for the provision of extension services)

- Sunyani Market Women Association (who successfully advocated for the for the provision of sheds to enhance trading of their farm produce)

- Zanlerugu-Langube Development Association (ZALDA) (who advocated for the rehabilitation of the irrigation dam in their community to support dry season farming activities.

- Jaman South Cooperative Plantain Growers Society

- Jomoro Cocoa Farmers Society, and many others

It was thought revealing that the extent to which Busac Fund advocacy has been of great assistance. For instance, in a dialogue a famer had this to say:

"We have been able to enroll our children in various levels of education including the university who are favorably competing with children from rich backgrounds since we are able to earn much income from our produce" Another has this to say:

"The absence of tertiary officers was a challenge to our business since all our livestock were dying of strange diseases and we did not know what to do. Thanks to the advocacy action, the officers are now living among us making them easily accessible and we hardly record any death with regards to our birds nor the livestock's. We appreciate the Busac Fund for all they have done for us". These and many more other testimonies were given as to the significant role played by Busac Fund in sustainability of policy advocacy in the agricultural sector.

In the industry sector, Busac Fund has also made significant contributions towards policy advocacy sustainability. Collaborations were made with major stakeholders in this industry such as the ministry of trade and industry and the ministry of food and agriculture in conjunction with industry players including the Oil Palm Industry, Printers and Publishers Associations, Sugar Policy Development Authorities and other similar associates in the industry. Several dialogues and round-table discussions with these organizations were strengthened to ensure good working relations and strategies that would accelerate growth in the industry. The Busac Fund in partnership with the Ghana Employers Association (GEA) and the trade union congress (TUC) identified that there is the need to formalize the informal sector and entrepreneurship development. Findings of the study further revealed that several businesses have been assisted by Busac Fund to boom their business operations. For instance, the advocacy action between the Parliament of Ghana and the Association of Ghana Solar Industries supported by Busac Fund resulted in the expansion of the manufacturer of solar equipment's in various forms. Success has also been 
achieved by securing basic infrastructure for artisans, advocacy skills development to save the plastic industry and many other similar assistants and projects supported by Busac Fund. The policy advocacy sustainability by Busac fund also extends to the services sector of the economy with support to many Small and Medium Enterprises (SMEs) and other service providers.

The Influence of BUSAC Fund Policy Advocacy on the Formulation and Implementation of Policies

Findings in this sub section of the study were based on information solicited with the questionnaires and interviews granted by some respondents. Specific information sought by the researcher and provided by respondents were on issues which were used as proxies for assessing the influence of policy advocacy by Busac Fund on policy formulation and implementation. Such issues included the status of business after policy advocacy, perception on advocacy influence on business, views on formulation and implementation of policy advocacy the factors that influence the formulation and implementation of advocacy and the overall satisfaction with policy advocacy.

In an interview, it was pointed out by the leader of Rural Organization of Women Farmers and Processing Development (ROWFAD) that

"we use advocacy by the help of Busac to break barrier for years that prevented our active involvement in local economic activities. Our members were supported through training skills and advocacy, effective dialoguing, record keeping and entrepreneurial skills that ensure survival and sustainable growth".

In another case, "it was noted by the Mwinbinbu Shea butter processors that "getting external support from the government and NGOs helped us to reduce the associated difficulties during processing. The advocacy support by Busac Fund dialogue assisted in the provisions of borehole for the factory". This ensure continuous implementation of our objective as a policy.

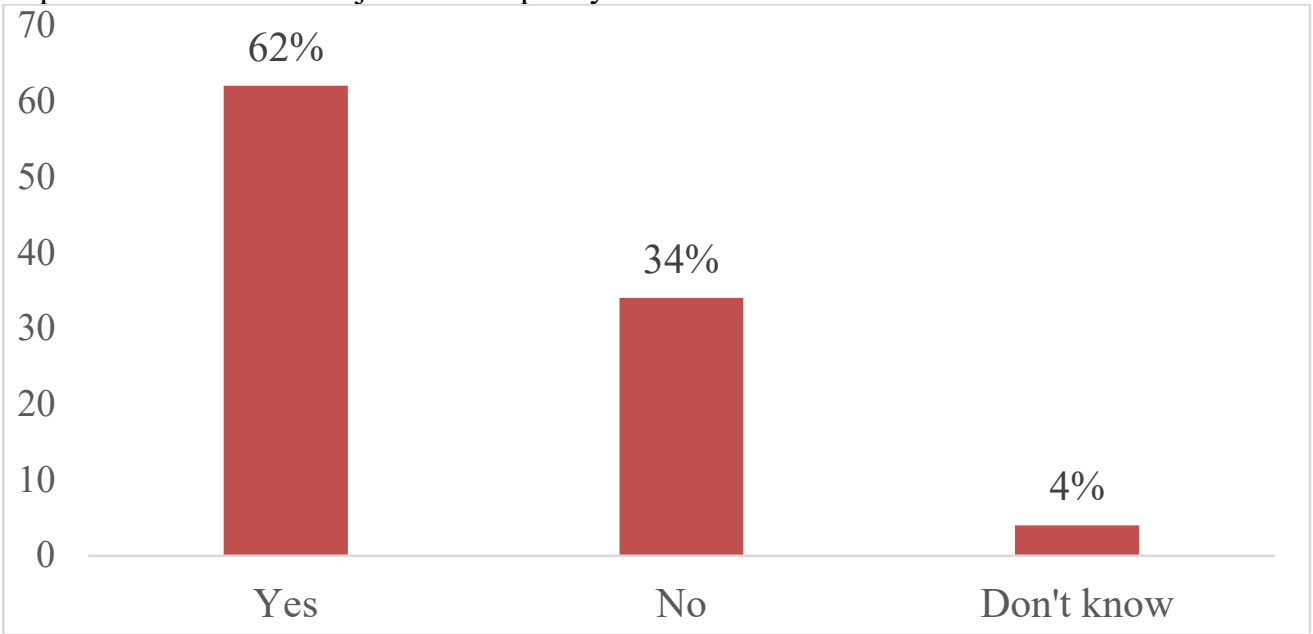

\section{Source: Field Data, 2018}

Figure 3: Respondents View on their Business Status after Policy Advocacy

The results depicted in Figure 2 above shows that majority of the respondents $(62 \%)$ were of the view that their business operations improved after the policy advocacy. However, 34\% of them perceived that their businesses have not seen any improvement despite the policy advocacy actions whiles the remaining 4\% were unable to tell as to their there has been an improvement or not. Finding here pointed out that there had been enhancement in the business of most of the beneficiaries through the assistance of Busac Fund. Leading an efficient fore-front in policy formulations and implementation by Busac Fund thus seems to have yielded a much better results to most individuals, which needs to be more extensive. Effective and efficient practice of such policy advocacy is very important so as to benefit others who have realized its influence on their businesses. An improvement in the status of grantee organizations businesses is an indication that policy advocacy to a large extent is having an influence on the formulation and implementation of policy in the business sector in Ghana. In an interview with a respondent, he stated

"Our crops were not doing well at all, we needed agriculture extension officers to come to our aid but the government provided no help. Nevertheless, we were assisted by Busac to form a formidable group that lead to an effective discussion with the agricultural ministry. This paved way for frequent inspection and advice from extension officers".

Another respondent has this to say,

"We have a good relationship with Busac, before their assistance, we were thinking of how best ensure our plastics manufactured can get a big market share. Busac in connection with the Ministry of Environment assisted us in the formation of the Association of Plastic Manufacturers, Ghana, which acts as a mouthpiece and talk on behalf of members when the need arises. We are able to link up well with the government and hence supply them plastic 
dustbins accoss bus terminals and other vantage positions for waste disposal which in turn helps the government in the implementation of "make Ghana clean" policy".

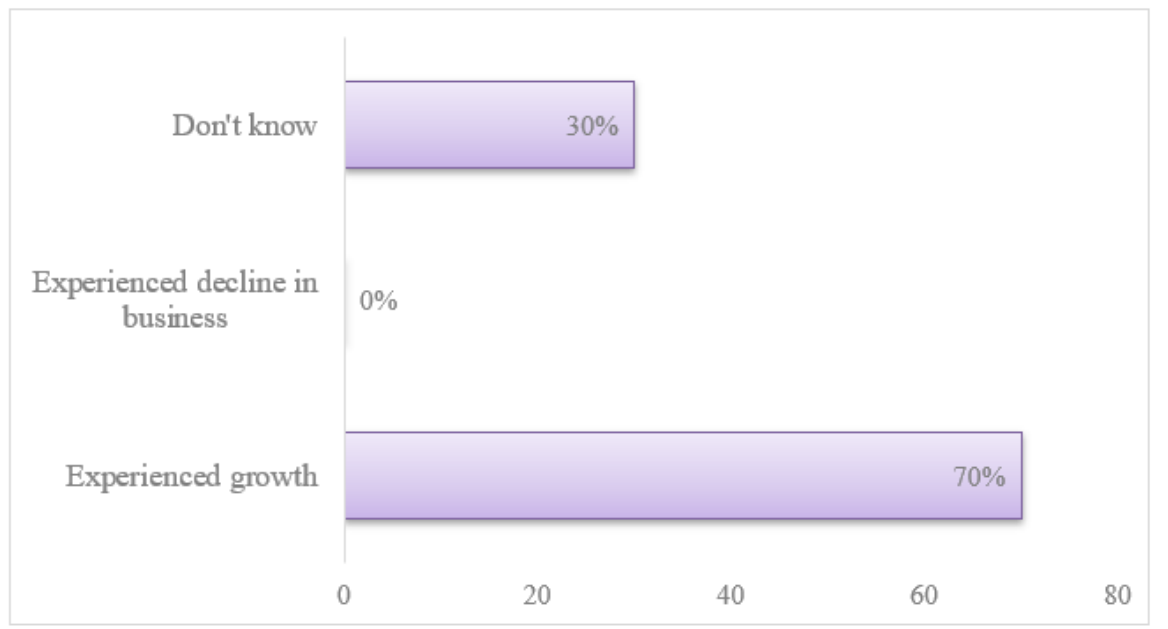

\section{Source: Field Data, 2018}

\section{Figure 4: Perceptions and Opinions on Policy Advocacy Influence on Business}

The study went further to probe further into the exact influence that policy advocacy has on the respondents businesses. From Figure 3, it is glaring that $70 \%$ of the businesses have experienced growth whiles the remaining $30 \%$ of the respondents do not know whether there has been growth in their businesses or not. Worth mentioning is the fact that none of the respondents have purported a decline in their business operations. These findings again demonstrates that policy advocacy has substantially influenced the business industry and hence the formulations and implementations of policies. The advocacy actions have improved the income levels of respondents, improved their business operations, improve their market access and at times provides an ease in the payment of membership dues. The efforts of Busac Fund in influencing the formulation and implementation of policies in the business environment is intend contributing to the growth is businesses.

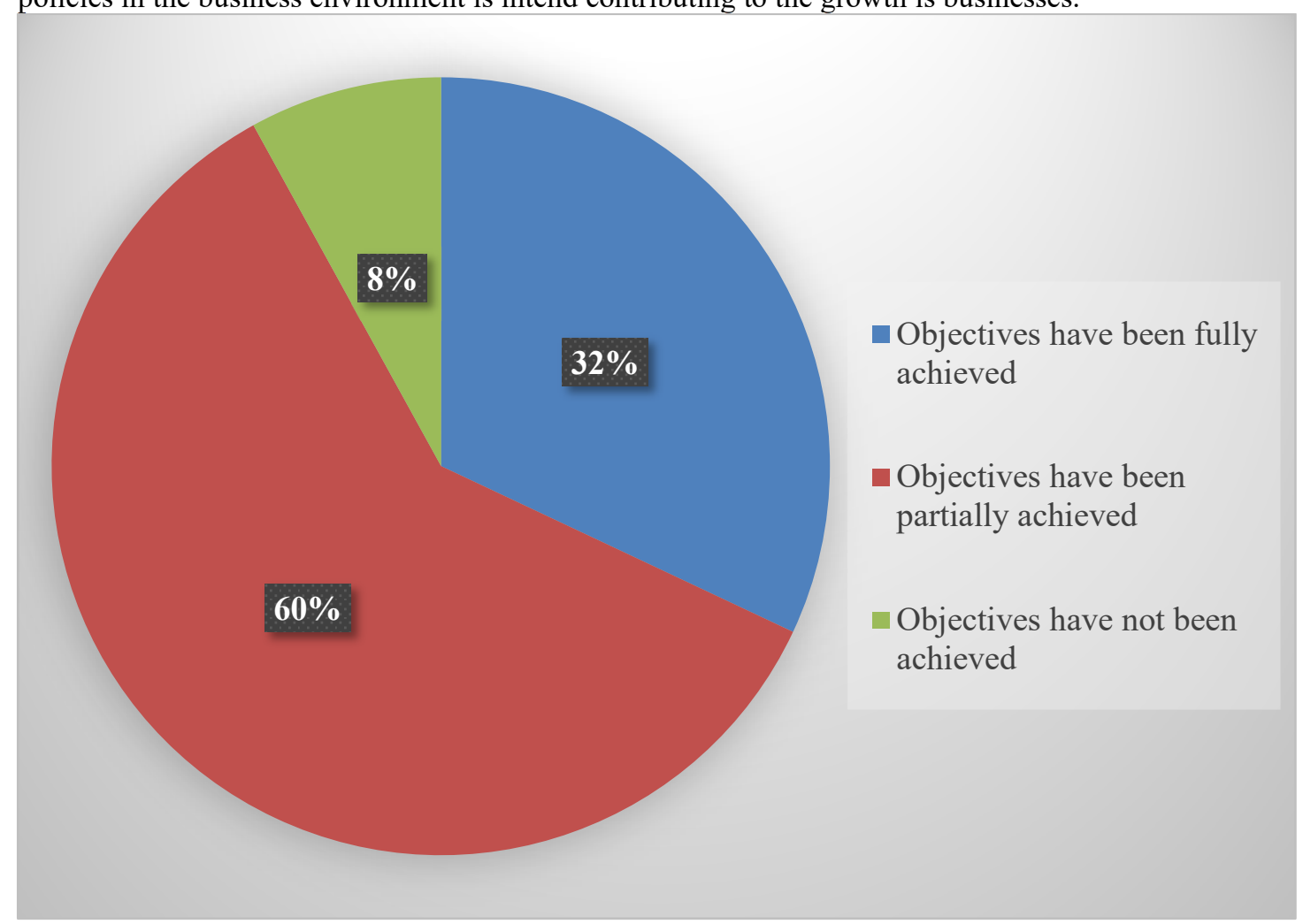

\section{Source: Field Data, 2018}

Figure 5: Distribution Respondent's Assessment of Policy Advocacy Implementations

Enquiries were also on the study concerning the views of respondents as to their level of assessment of policy advocacy implementations. Results depicted on figure 4 suggests that in accordance with the assessment of 
respondents it is declared by majority (60\%) that the objectives behind advocacy actions of Busac Fund has been partially achieved. A little above $30 \%$ also were also of the view that the objectives of Busac in advocating for policy formulations and implementations has been fully achieved. However, a little of $8 \%$ of the respondents do not believe that Busac has achieved their objectives. Generally, the Busac Fund had been opined by as am important medium for championing issues of policy formulations and implementation through their advocacy actions despite some few concerns of partial fulfillment of their objectives.

\section{Factor Aiding the Formulation and Implementation of Policy Advocacy}

In ascertaining the influence of policy advocacy on the formulation and implementation of policies, the study also deemed it necessary and examine some important factors that plays a major role in policy formulation and implementations. Results are depicted on the Table 1.

Table 1: Distribution of Factors that Aids in Formulation and Implementation of Policy Advocacy

\begin{tabular}{lr}
\hline & Response \\
\hline Already trying in our own small ways before the BUSAC fund grant & $62 \%$ \\
The ministry has shown a lot of interest and contributed greatly & $76 \%$ \\
The issue at stake was so important that stakeholders could not ignore it & $52 \%$ \\
The media played a key role in highlighting the issue & $36 \%$ \\
International pressure brought to been on government and public officials & $74 \%$ \\
\hline
\end{tabular}

\section{Source: Field Data, 2018}

Since variables in this section of the chapter were measured on the basis of multiple response, the total percentage of responses were more than $100 \%$ because a respondent can pick more than one variable. Results from the table shows that most of the Grantee organizations were already putting in their little efforts in advocating for policies before the Busac Fund. This is disclosed by $62 \%$ of the responses, inferring that self interest in policy advocacy by many of the guaranteed organizations was a driving force in the formulation and implementation of policies. It is further indicated that the ministry often shows a lot of interest in issues relating to policies in the business sector and greatly contribute towards formulation and implementations. Other stakeholders in the business sector were also acknowledged by respondents as major players in the formulation and implementation of policies. With a high response of $74 \%$, it was also disclosed that pressure from international organizations on the government and public officials aids in policy formulation and implementation. Nevertheless, the media was less credited by respondents as major player's inn highlighting issues towards policy formulation and implementation. It is deduced that the media needs to be more involved in championing policy advocacy formulations and implementations.

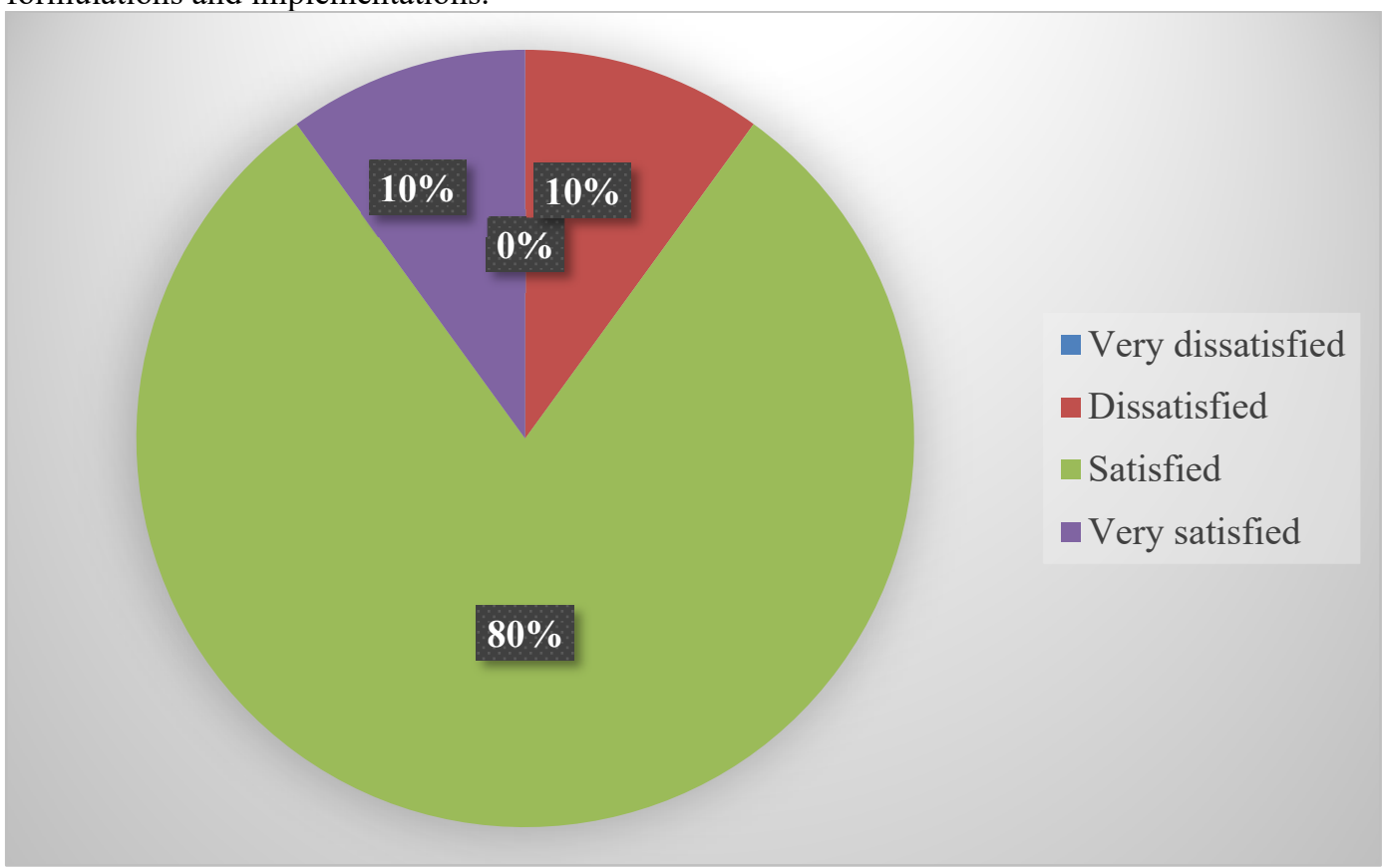

\section{Source: Field Data, 2018}

Figure 6: Respondents Overall Satisfaction with policy formulation and implementation

The study also attempted to examine the overall satisfaction of Grantee organizations with policy 
formulations and implementations. Findings above shows an overwhelming proportion of respondents $(90 \%)$ were satisfied with the formulation and implementation of policies powered by advocacy actions of Busac Fund. Only a few comprising $10 \%$ were dissatisfied.

\section{Challenges Hindering the Efforts of BUSAC in the Delivery of their Mandate}

Despite the many success stories, contributions and the influence of the Busac Fund in the private sector business dialogues towards policy formulation and implementation, there has been challenges in the delivery of their mandate as well. This objective of the study was accomplished by interviewing 5 officials of the Busac Fund on challenging issues effecting their progress and the review of archival reports of Busac Fund.

One of the main challenges revealed was the issue of poor collaboration among technical assistants of Busac Fund (monitors, trainers and data collectors) who ensures effectiveness, efficiency and sustainability of policy advocacy programmes/projects and grantee organizations. It was revealed that the grantee organizations often display negative attitude towards these assistants. As stated by a Busac Fund official

"Our business support personnel's (BSPs) often complains about the behavior and attitude of individual grantees and organizations. The grantees after getting their proposals approved do not want to work with the BSPs anymore and develop negative attitude towards them instead of positively discontinuing the relationship that existed between them".

As a result of such poor relationships, there is often a delay in the delivery of projects undertaken through Busac Fund initiatives due to low/weak capacity of grantees. In an interview, it was further disclosed that

"The difficulties with the relationship between grantees and our officials creates a difficulty for BSPs to assess fees from the grantees. The problem is mostly faced with weaker/smaller PSOs (Private Sector Organizations) who were assisted by BSPs".

On the part of training, there has also been complains that the grantees mostly do not turnout for training programmes. This is to say most training is targeted at few members of the grantees, with no post-training targeted at new or other members who have not benefited. This often affect grantees in implementations, since these members may not understand how to advocate in order to assist their associations. An official said

"Some grantees tend to assume that, the training organized for them is not necessary, and this sometimes delays the time of training as well as effective participations".

Another major challenge has to do with low commitment from the supervising ministry and low commitment from members. It was deduced that it was sometimes difficult to get government officials to the table in discussing issues in the business space. It was revealed that at times the government makes commitment to vital policy advocacy issues but fails to deliver on their commitment.

Furthermore, a key challenge identified which was critical for the Busac Fund and its stakeholder's lies on the private sector attempting to influence the development and implementation of regulatory instruments that would lead to improvement in the business environment for its operators.

\section{CHAPTER FIVE SUMMARY OF FINDINGS, CONCLUSIONS AND RECCOMENDATIONS Introduction}

This chapter of the study delves into the conclusions of the study on the basis of findings and also give recommendations on the study for decisions making.

\section{Summary of Findings}

The study employed both quantitative data gathered with questionnaires and qualitative data solicited by interviews and text data (from archival records) to satisfy its objectives. Findings of the study revealed that Busac Fund has implemented advocacy strategies in the private business sector in order to ensure policy sustainability. These were done through their numerous contributions to serving as an interest group to facilitate effective and efficient policy implementation in the sector of agriculture, industry and services. Busac continuously connect with private sector businesses and stand as a driving force to collaborate with the government to discuss policies of vital concern and influences changes towards sustainability and ensuring a general conducive business environment.

To ensure that private sector businesses are able to cope with the business environment and existing policies in the country, business organizations by the help of Busac receive training of various forms that enable them strive or survive. In the agriculture sector for instance, sustainability of policy advocacy is done by empowering farmers to improve upon their skills by training, giving financial support and business management training. They also support by giving businesses organizations grants for improvement in the growth and sustainable productions.

Further findings revealed that about $62 \%$ of the businesses covered by the study have experienced some improvement in their businesses after advocacy by Busac. There has been improvement in the formulations and implementations of policy in the private sector. This was disclosed by the advocacy activities of Busac that has brought changes to policy formulations and implementation. Busac however in their efforts were confronted with 
challenges such as poor collaboration between grantee organizations and Busac Fund officials, low commitment of government and inadequate legislative regulatory instruments.

\section{Conclusions}

Policy change offers a new picture of interest group influence in the policy making process. Interest group influence is common across venues, time periods and issue areas. Influence by advocacy groups through general support and lobbying is the most commonly cited factor. A few prominent groups including the Busac Fund has been credited with many different policy enactments and play central roles in the influence network. According to the literature review of cited policy reforms and formulation, interest group influence was common throughout most of the period, especially in the areas of civil rights \& liberties, environmental policy, agriculture, and transportation etc.

Interest group influence may not follow directly from group or resource mobilization. The measures of group activity may be unlikely to be associated with influence, even though a few groups regularly influence outcomes. General support for policy changes by interest groups recognized as stakeholders may be the most important route to influence. The policy process should be an effective tool of influence in policy reforms and formulation.

Interest groups likely play an important role in producing significant policy change. In order to ensure the sustainability of policy advocacy in Ghana, the Busac Fund has done its best through various contributions and making sure they have a significant influence on the formulations and implementation of policies. Findings revealed that Busac Fund laid emphasis on building capacity in developing private sector businesses. Through collaboration with government and other stakeholders including private sector institutions, policies have been formulated and implemented to ensure a conducive business environment despite some few challenges encountered. It is concluded that Busac Fund in conducting such lobbying role in policy formulation and implementation has been beneficial to many private businesses and improvement in individuals lives in general.

It is further concluded that, Busac Fund has influenced the policy formulation and implementation in the country especially in major sectors such as agriculture (sugar policy development, cashew nut industrial policy traceability policy with data base for tuber expert etc.), services sector (tax reduction, guidance for rural banking etc) and the industrial sectors (involvement and participation of local printers and publishers in the supply of school textbooks, construction of farming area roads, implementation of solar energy policy etc.). There were however hindered by some challenges in delivering on their objective of policy advocacy. These included poor nature of collaboration between grantee organizations and Busac Fund officials, low commitment on the part of government and inadequate legislative regulatory instruments that would improve the business environment.

\section{Recommendations}

It was deduced that not every grantee organization was greatly benefiting from the advocacy initiatives of Busac Fund and thus not satisfied. It is thus important that strategies are well implemented to get everyone involved to make such a curtail advocacy programme more effective, efficient and beneficial to all. Busac also need to review their systems of dealing with grantee organizations which would allow for a peaceful collaborations with Busac officials.

On the supply side, government needs to improve the quality of its engagements. The use of non-technical language, equal partnerships, accountability, flexibility and inclusiveness are all matters that need to be addressed to ensure that government is truly committed to the process. On the demand side, citizen groups, think tanks and CSOs must bring social issues to the table and proactively mobilise social, human, financial and technical resources to sustain discussions and ensure that issues they raise are addressed fully.

It must also be noted that multi-stakeholderism, which brings citizens closer to decision making processes, has benefits both intrinsically and instrumentally. Intrinsically, participation in multi-stakeholder decision making processes symbolizes the democratic rights of citizens to participate in decisions that affect them. Instrumentally, such processes lead to better decisions and the possibility of social policies being successful because of ownership and support from engaged citizens.

While it is not the only requirement for ensuring success of social policies, the absence of or inadequate multistakeholder engagement is the surest way for social policies to fail. That is why we are happy to acknowledge the intensive and extensive consultations that characterised the review and formulation of the National Social Protection Strategy and Social Policy Framework respectively. As the process moves towards the eventual formulation of a national social policy and Bill, it is our sincere hope that the lead agencies will continue to harness the ideas and contribution of civil society organizations.

\section{References}

Baumgartner, F., \& Leech, B. (1998). Basic interests: The importance of groups in politics and in political science. Princeton: Princeton University Press.

Baumgartner, F., \& Bryan, D. (1991). Agenda Dynamics and Policy Subsystems. Journal of Politics(53), 1044 
1074.

Baumgartner, F., Berry, J., Hojnacki, M., Kimball, D., \& Leech, B. (2009). Lobbying and Policy Change: Who Wins, Who Loses, and Why. Chicago: University of Chicago Press.

Baumgartner, F., Bryan, D., \& Wilkerson, J. (2002). Studying Policy Dynamics. In F. Baumgartner, \& D. Bryan, Policy Dynamics. Chicago: University of Chicago Press.

Berry, J. (1999). The New Liberalism: The Rising Power of Citizen Groups. Washington DC: Brookings Institution.

Boin, A., Hart, P., \& McConnell, A. (2009). Crisis Exploitation: Political and Policy Impacts of Framing Contests. Journal of European Public Policy, 16(1), 81-106.

Braun, B., \& Carke, V. (2006). Using thematic analysis in psychology. Qualitative Research in Psychology, 3(2), 77-101.

Bryson, J., \& Anderson, S. (2000). Applying large-group interaction methods in the planning and implementation of major change efforts. Public Administration Review, 60(2), 143-153.

Burns, N., \& Grove, S. (2003). Understanding Nursing Research. Pennsylvania: Saunders.

Burns, N., \& Grove, S. K. (2003). Understanding Nursing Research (3 ed.). Pennsylvania: Saunders.

Burstein, P., \& Linton, A. (2002). The impact of political parties, interest groups, and social movement organizations on public policy: Some recent evidence and theoretical concerns. Social Forces, 81(2), 380408.

Business Sector Advocacy Challenge Fund (BUSAC). (2016).

Chapman, J., \& Wameyo, A. (2001). Monitoring and evaluating advocacy: A scoping study. Retrieved from http://www.actionaid.org

Cohen, S., Eimicke, W., \& Heikkila, T. (2013). The Effective Public Manager: Achieving Success in Government Organizations. San Francisco: Jossey-Bass.

Cormack, D. F., \& Benton, D. C. (1996). The Research Process in Nursing (3 ed.). Oxford: Blackwell Science.

Couchman, W., \& Dawson, J. (1995). Nursing and Health-Care Research. London: Scutar.

Craig, R. L., Holly, C. F., Jada, F. W., \& Martha, M. P. (2010). Public Health Professionals as Policy Entrepreneurs: Arkansas's Childhood Obesity Policy Experience. American Journal of Public Health, 100(11), $2047-2052$.

De Figueiredo, D., \& Silverman, B. (2006). Academic earmarks and the returns to lobbying. Journal of Law and Economics, 49(2), 597-626.

Denhardt, R., \& Denhardt, J. (2000). The new public service: Serving rather than steering. Public Administration Review, 60(6), 549-559.

Donor Committee for Enterprise Development (DCED). (2008). Supporting Business Environment Reforms: Practical Guidance for Development Agencies. Accra: DCED.

Duffy, R. (1997). Nuclear Politics in America: A History and Theory of Government Regulation. Kansas: University Press of Kansas.

Fowler, L. (1994). Political Entrepreneurs, Governing Processes and Political Change: In New Perspectives on American Politics. Washington: CQ Press.

Gallagher, D., \& Jackson, S. (2008). Promoting community involvement at brownfields sites in socioeconomically disadvantaged neighborhoods. Journal of Environmental Planning Management, 5, 615-630.

Grantmakers In Health. (2005). Funding health advocacy. Washington, D.C: GIH Issue Brief.

Grossmann, M. (2012). Interest group influence on US policy change: An assessment based on policy history. Interest Groups \& Advocacy, 1(2), 171-192.

Grossmann, M., \& Dominguez, C. (2009). Party coalitions and interest group networks. American Politics Research, 37(5), 767-800.

Gupta, J. (2009). Driving Forces in Global Fresh Water Governance. In Water Policy Entrepreneurs: A Research Companion to Water Transitions Around the World. Northampton: Edward.

Guthrie, K., Louie, L., David, T., \& Crystal Foster, C. (2005). The challenge of assessing policy and advocacy activities: Strategies for a prospective evaluation approach. San Francisco, CA: Blueprint Research and Design.

Hall, R., \& Wayman, F. (1990). Buying time: Moneyed interests and the mobilization of bias in congressional committees. American Political Science Review, 84(3), 797-820.

Heaney, M. (2004). Outside the issue Niche: The multidimensionality of interest group identity. American Politics Research, 32(6), 611-651.

Heinz, J., Laumann, E., Nelson, R., \& Salisbury, R. (1993). The Hollow Core: Private Interests in National Policy Making. Cambridge: Harvard University Press.

Henry, A. (2011). Ideology, power and the structure of policy networks. Policy Studies Journal(39), 361-383.

Holyoke, T. (2003). Choosing battlegrounds: Interest group lobbying across multiple venues. Political Research Quarterly, 56(3), 325-336.

Huitema, D., \& Meijerink, S. (2010). Realising Water Transitions: The Role of Policy Entrepreneurs in Water Policy Change. Ecology and Society, 15(2), 26-50. 
International Finance Corporation (IFC). (2011). development through the private sector. Washington, D.C.: Pennsylvania Avenue.

Jansson, B. (2010). Becoming an effective policy advocate: From policy practice to social justice (5 ed.). Belmont, CA: Thomson Brooks/Cole.

Kadushin, C. (2012). Understanding social networks. Oxford: Oxford University Press.

Kastens, B., \& Newig, J. (2008). Will participation foster the successful implementation of the water framework directive? The case of agricultural groundwater protection in Northwest Germany. Local Environment, 13(1), 27-41.

Kingdon, J. (1995). Agenda setting, Public policy: The essential readings. Boston: Little Brown.

Knupfer, N., \& McLellan, H. (1996). Descriptive research methodologies. In D. Jonassen, Handbook of research for educational communications and technology (pp. 1196-1212). New York: Macmillan.

Koenig, H. (2005). Empowerment in local government administration: The case of Elgin, Illinois. The Public Sector Innovation Journal, 10(1).

Kumekpor, T. (2003). Research methods and techniques of social research. Accra: SonLife Press \& Services.

Laing, M. (2015). Scientists and Policy Influence: A Literature Review . Melbourne: Cooperative Research Centre for Water Sensitive Cities.

Levin, M., \& Sanger, M. (1994). Making Government Work: How Entrepreneurial Executives Turn Bright Ideas into Real Results. San Francisco: Jossey-Bass.

Mahoney, C. (2008). Brussels Versus the Beltway: Advocacy in the United States and the European Union. Washington DC: Georgetown University Press.

McLaverty, P. (2011). Participation. In M. Bevir, The Sage handbook of governance (pp. 402-417). Thousand Oaks, CA: Sage Publications.

Meiring, M. (2009). The nature and importance of policy analysis and evaluation. South Africa: University of Fort Hare.

Melnick, R. (1994). Between the Lines: Interpreting Welfare Rights. Washington DC: Brookings Institution.

Mintrom, M., \& Norman, P. (2009). Policy Entrepreneurship and Policy Change. Policy Studies Journal, 649-667.

Moore, M. (2011). Can public-policy advocacy be taught? Or learned? The Philanthropist, 23(4), 471-480.

Nalbandian, J. (1999). Facilitating community, enabling democracy: New roles for local government managers. Public Administration Review, 59(3), 187-197.

Oxford Policy Management Report. (2014). Evaluation of the Business Sector Advocacy Challenge (BUSAC) Fund, Ghana. Ghana: Ministry of Foreign Affairs of Denmark.

Patashnik, E. (2003). After the public interest prevails: The political sustainability of policy reform. Governance, $16(2), 203-234$.

Polit, D. F., \& Hungler, B. P. (1999). Nursing Research: Principles and Methods (Lippincott ed.). Philadelphia: 6.

Polit, D., \& Hungler, B. (1999). Nursing Research: Principles and Methods. (6 ed.). Philadelphia: Lippincott.

Polsby, N. (1984). Political Innovation in America: The Politics of Policy Initiation. New Haven: Yale University Press .

Qureshi, Z. (2016). Meeting the Challenge of Sustainable Infrastructure: The Role of Public Policy. Washington DC: Global Economy and Department .

Reid, E. (2006). Understanding the word advocacy: Context and use In Nonprofit advocacy and the policy process: Structuring the inquiry into advocacy. Washington, DC: The Urban Institute.

Reisman, J., Gienapp, A., \& Stachowiak, S. (2007). A guide to measuring advocacy and policy. Casey Foundation.

Sabatier , P. (1998). The advocacy coalition framework: revisions and relevance for Europe. Journal of European Public Policy, 5(1), 98-130.

Sabatier, P., \& Jenkins-Smith, H. (1999). The Advocacy Coalition Framework: An assessment. In P. Sabatier, Theories of the Policy Process (pp. 117-166). Boulder: Westview Press.

Sabatier, P., \& Weible, C. (2007). The advocacy coalition framework: Innovations and clarifications. Boulder: Westview Press.

Schlozman, K., \& Tierney, J. (1986). Organized Interests and American Democracy. New York: Harper \& Row.

Schmid, H., Bar, M., \& Nirel, R. (2008). Advocacy activities in nonprofit human service organizations: Implications for policy. Nonprofit and Voluntary Sector Quarterly, 37, 581-602.

Scholte, J. (2002). What Is Globalization? The Definitional Issue - Again. Warwick: The University of Warwick.

Smith, M. (2000). American Business and Political Power: Public Opinion, Elections, and Democracy. Chicago, IL: University of Chicago Press.

Sprechmann, S., \& Pelton, E. (2001). Advocacy tools and guidelines: Promoting policy change. A resource manual for CARE program managers. Retrieved from http://www.care.org/getinvolved/advocacy/tools/english

Start, D., \& Hovland, I. (2004). Tools for policy impact: a handbook for researchers. London: Overseas Development Institute.

Studlar, D. (2002). Tobacco Control: Comparative Politics in the United States and Canada. Toronto: University 
of Toronto Press.

Teodoro, M. (2011). Bureaucratic Ambition: Careers, Motives, and the Innovative Administrator . Baltimore: Johns Hopkins University Press.

True, James, L., \& Glenn, U. (2007). Saying 'Yes', “No', and “Load Me Up' to Guns in America. Ameican Journal of Public Administration, 216-241.

Walker Jr, J. (1991). Mobilizing Interest Groups in America. Ann Arbor: University of Michigan Press.

Witko, S. (2006). PACs, issue context, and congressional decision-making. Political Research Quarterly, 59(2), 283-295.

Xu, J. (2005). Why do minorities participate less? The effects of immigration, education, and electoral process on Asian American voter registration and turnout. Social Science Research, 34, 682-702.

\section{A: Questionnaire for Grantee Organization}

\section{Appendix}

Please tick the relevant box $[\mathrm{X}]$ for each question.

Name of Organization:

1. Has the business environment improved after policy advocacy?

[ ] Yes [ ] No [ ] Don't Know

2. How has the policy advocacy influenced your business?

[ ] Experienced growth [ ] experienced decline in business

[ ] Don't know

3. Which of the following has happened as a result of advocacy efforts? Please tick as many as applied.

[ ] increase incomes [ ] enhanced operations [ ] improved market access [ ] increased in dues paying membership please specify.

4. How do you assess the implementation of the advocacy action?

[ ] objectives have been fully achieved

[ ] objectives have been partially achieved

[ ] objectives have not been achieved

5. What factors aided the formulations and implementation of your policy advocacy? Please tick as many as applied.

[ ] already trying in our own small ways before the BUSAC fund grant

[ ] The ministry has shown a lot of interest and contributed greatly

[ ] the issue at stake was so important that stakeholders could not ignore it

[ ] The media played a key role in highlighting the issue

[ ] international pressure brought to been on government and public officials

6. Please rate your overall satisfaction with the policy formulation and implementation?

[ ] Very dissatisfied [ ] Dissatisfied [ ] Satisfied [ ] Very satisfied 
Institutional Review Board

Andrews University

Berrien Springs, MI 49104-03

Hse No. C49/14

Nii Bonne Crescent

Dzorwulu - Accra

P.O. Box 30507 KIA

Dear Sir,

Tet: +233 (0) 302780178 Email: contact@busac.org Website: unw. ousac ora

\section{LETTER OF CONSENT TO CONDUCT RESEARCH - MR. SAMUEL ASIHENE} NYAMPONG

December 20, 2017

RESEARCH TOPIC: "THE ASSESSMENT OF BUSINESS SECTOR ADVOCACY CHALLENGE (BUSAC) FUND GRANTEES INFLUENCING POLICY REFORMS IN GHANA WITH EMPHASIS ON SUSTAINABILITY OF POLICY ADVOCACY".

We have received an application from Mr. Samuel Asihene Nyampong, a student of Andrews University to undertake a research work on the topic: "The Assessment of Business Sector Advocacy Challenge (BUSAC) Fund grantees influencing policy reforms in Ghana with emphasis on sustainability of policy advocacy".

The research project will commence on $15^{\text {th }}$ January, 2018 until $15^{\text {th }}$ April 2018.

This letter is to inform your outfit of the BUSAC Fund's consent for the researcher to conduct a study on the above research topic.

Thank you

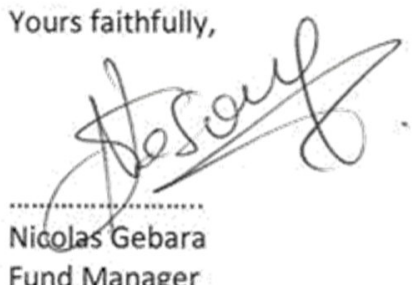

